\title{
Are magnetite spherules capable of carrying stable magnetizations?
}

\author{
Weixin Xu, Rob Van der Voo, and Donald R. Peacor \\ Department of Geological Sciences, University of Michigan, Ann Arbor
}

\begin{abstract}
To determine if magnetite spherules extracted from ancient carbonate rocks can carry ancient remanent magnetizations, electron microscope observations and magnetic data have been obtained for more than 100 individual spherules extracted from the Jurassic Twin Creek limestone, Wyoming, and the Mississippian Leadville limestone, Colorado. Two categories of surface textures (smooth and patterned) correlate with different hysteresis parameters. Spherules with patterned surfaces (Group $A$ ) have ratios of saturation remanent magnetization to saturation magnetization $\left(\mathrm{M}_{\mathrm{Sr}} / \mathrm{M}_{\mathbf{S}}\right)<0.1$ and ratios of remanent coercive force to coercive force $\left(\mathrm{H}_{\mathrm{cr}} / \mathrm{H}_{\mathrm{c}}\right)$ mostly $>3$. Most spherules with smooth surfaces (Group B) have $0.1<\mathrm{M}_{\mathrm{Sr}} / \mathrm{M}_{\mathrm{S}}<0.3$ and $\mathrm{H}_{\mathrm{Cr}} / \mathrm{H}_{\mathrm{C}}<3$. The pattemed surfaces consist of (1) parallel dendritic nets with units $\approx 1 \mu \mathrm{m}$ wide, (2) platelets with widths of 1 to $3 \mu \mathrm{m}$, (3) mosaic surface units with diameters between 2 and $5 \mu \mathrm{m}$; each of these surface elements consists of a single crystal, as verified by selected-area electron diffraction patterns showing sharp spots, whereas the spherules as a whole show multicrystalline patterns by X-ray diffraction. The $M_{S r} M_{S}$ and $H_{c}$ values of group $A$ increase with decrease in grain size; these Group A magnetite spherules are undoubtedly multi-domain in character and are unlikely to carry stable ancient remanences. The smooth-surfaced Group B spherules are not very abundant ( $<8 \%$ of the entire population) and have pseudo-single-domain (PSD) or multi-domain (MD) magnetic properties; they may carry ancient remanences, although we infer that single-domain (SD), non-spherical, submicrometer magnetite is the principal carrier of remanence in most carbonates.
\end{abstract}

\section{Introduction}

Magnetite spherules extracted from limestones have been inferred to be authigenic in origin and to carry ancient secondary magnetizations [McCabe et al., 1983; Horton et al., 1984]. However, spherical magnetite grains have also been found in unremagnetized Paleozoic carbonates from Indiana and Alabama [Suk et al., 1992]. Halgedahl and Suk [1992] studied the demagnetization characteristics of magnetite spherules vs. whole-rock specimens, and concluded that the spherules contribute very little to natural remanent magnetization (NRM). Moreover, our own preliminary measurements of two magnetite spherules from the Twin Creek limestone yielded $\mathrm{M}_{\mathrm{Sr}} / \mathrm{M}_{\mathrm{S}}<0.05$ [Xu et al., 1993], values

\section{Copyright 1994 by the American Geophysical Union.}

which are characteristic of synthetic MD magnetite [Day et al., 1977]. Thus an increasing body of evidence suggests that magnetite spherules are not the carrier of pervasive remagnetizations in carbonate rocks. Nevertheless, according to Suk and Halgedahl [1992], some magnetite spherules can have $M_{S r} / M_{S}$ values greater than 0.3 and $H_{c r} / H_{c}$ values less than 3 , indicating that some spherules exist that may be capable of carrying a stable magnetization. This implies that more than one kind of magnetite spherule may occur in carbonates. In order to clarify which kinds of magnetite spherules, if any, are capable of carrying stable ancient magnetization, we have carried out electron microscope observations and measured magnetic hysteresis parameters of individual magnetite spherules extracted from limestones.

\section{Samples and Methods}

The samples used in this study were collected from the Jurassic Twin Creek Formation, Wyoming, and the Mississippian Leadville limestone, Colorado. Both limestones were deposited in a shallow, stable shelf environment and remagnetized in late Mesozoic and Tertiary time [McWhinnie et al., 1990; Horton et al., 1984].

Magnetic extracts were prepared by dissolving crushed rock samples in dilute buffered acetic acid [McCabe et al., 1983] and separating the magnetite component of the insoluble residue with a rare-earth permanent magnet.

Single magnetite spheres were selected using an optical microscope and placed on glass plates. After being gold coated, the spherules were examined using a scanning electron microscope (SEM). The SEM used is a Hitachi S-570, equipped with a Kevex Quantum energy dispersive analysis (EDA) system. The magnetite grains were then enclosed within a small drop of nail enamel for convenience in handling during magnetic measurements. Hysteresis properties of the single magnetite spherules were measured on an alternating gradient force magnetometer (AGFM) in the Institute for Rock Magnetism (IRM) at the University of Minnesota.

A few grains were selected on the basis of hysteresis values for observation in a scanning transmission electron microscope (STEM). The STEM used is a Philips CM-12 fitted with a Kevex Quantum EDA system. The crystalline states of whole spheres were studied using spheres attached to glass fibers mounted on a precession single-crystal $\mathrm{X}$-ray machine.

\section{Results}

Magnetite spherules found in the Twin Creek limestone and Leadville limestone have identical size ranges and surface textures. All were almost perfectly round spheres with diameters ranging from several to $85 \mu \mathrm{m}$ (Figure 1). SEM observations showed that grains vary in surface texture on the 


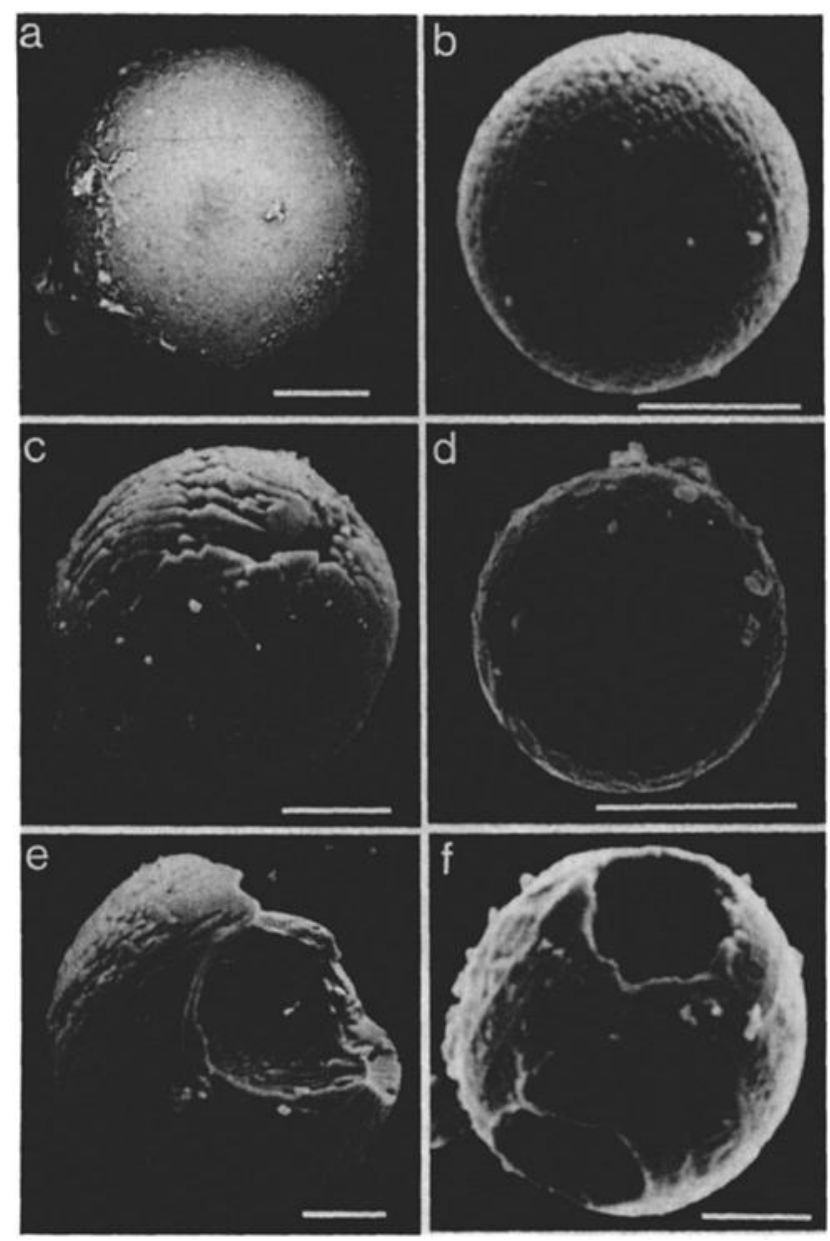

Figure 1. SEM images illustrating the typical surface textures of magnetite spherules extracted from carbonates: (a) smooth, (b) dendritic, (c) platy, (d) mosaic, (e) dendritic texture extending to the interior of the grain, (f) hollow grain. Scale bar $=10 \mu \mathrm{m}$.

basis of which they can be divided into four groups that have: (1) smooth surfaces without discernible internal structures (Figure 1a); (2) parallel dendritic nets with units $\approx 1 \mu \mathrm{m}$ wide (Figure 1b); (3) platelets with widths $\approx 1$ to $3 \mu \mathrm{m}$ (Figure 1c); and (4) mosaic patterns of platelets with diameters from 2 to 5 $\mu \mathrm{m}$ (Figure 1d). Those with a dendritic surface are most common, and those with a smooth and mosaic surface are rare. Some grains have surface textures that are transitional to these categories, although the examples of Figure 1 are representative of $\approx 95 \%$ of the total population. Energydispersive analyses of most spherules revealed no cations other than iron. However, smooth spherules contained minor $\mathrm{Si}, \mathrm{Ca}$, and $\mathrm{Al}$ distributed heterogeneously, as inclusions.

Individual plates forming the surface of patterned grains are observed to display straight, subparallel boundaries with a preferred orientation and angular relations consistent with octahedral faces of single crystals oriented normal to a threefold axis. Indeed, the curved surfaces are typical of crystals with a pronounced mosaic structure, in which small defect-free single crystals are separated by zones of high defect density that cause the defect-free domains to be slightly misoriented with respect to one another [Buerger, 1960]. The subparallel surface features of the dendritic crystals likewise are consistent with locally ordered crystal structures. The mosaic grains have individual subunits, all of the same approximate shape, showing outlines approximating three-fold symmetry. Such a morphology is consistent with a sphere that consists of individual units with three-fold axes diverging from the sphere center and separated by zones of high defect density. The units are regularly arrayed, each surrounded by six other units in a hexagonal, closest-packed-like arrangement. With the exception of the spherules with smooth surfaces, therefore, grains exhibit textures that resemble an assemblage of single crystals, modified by defects.

Magnetic hysteresis measurements were made in the IRM at the University of Minnesota on more than 100 individual spheres. Although the AGFM (Model MicroMag) theoretically has a sensitivity of $10^{-2} \mathrm{nAm}^{2}$, a more realistic lower limit is about 100 times higher. The saturation magnetization $\left(M_{\mathbf{S}}\right)$ of grains with diameters less than $15 \mu \mathrm{m}$ is generally less than 2 $\mathrm{nAm}^{2}$. Only results for the 56 grains with grain size $\geq 15 \mu \mathrm{m}$ that gave $M_{S}$ values of $>2 \mathrm{nAm}^{2}$ are considered sufficiently meaningful to be discussed below.

Magnetic hysteresis data were processed to remove the contributions from the sample holder and other paramagnetic or diamagnetic materials. Figure 2 shows representative hysteresis loops that are typical of MD grains (Figure 2a) and PSD grains (Figure 2b), respectively. Both loops are different from the so called wasp-waisted loops which were described for bulk rock samples by Jackson [1990]. Most grains have $\mathrm{M}_{\mathrm{Sr}} / \mathrm{M}_{\mathrm{S}} \approx 0.05$. Only three grains have $0.1<\mathrm{M}_{\mathrm{sr}} / \mathrm{M}_{\mathrm{S}}<0.3$ (Figure 3a). These three grains all have a smooth surface

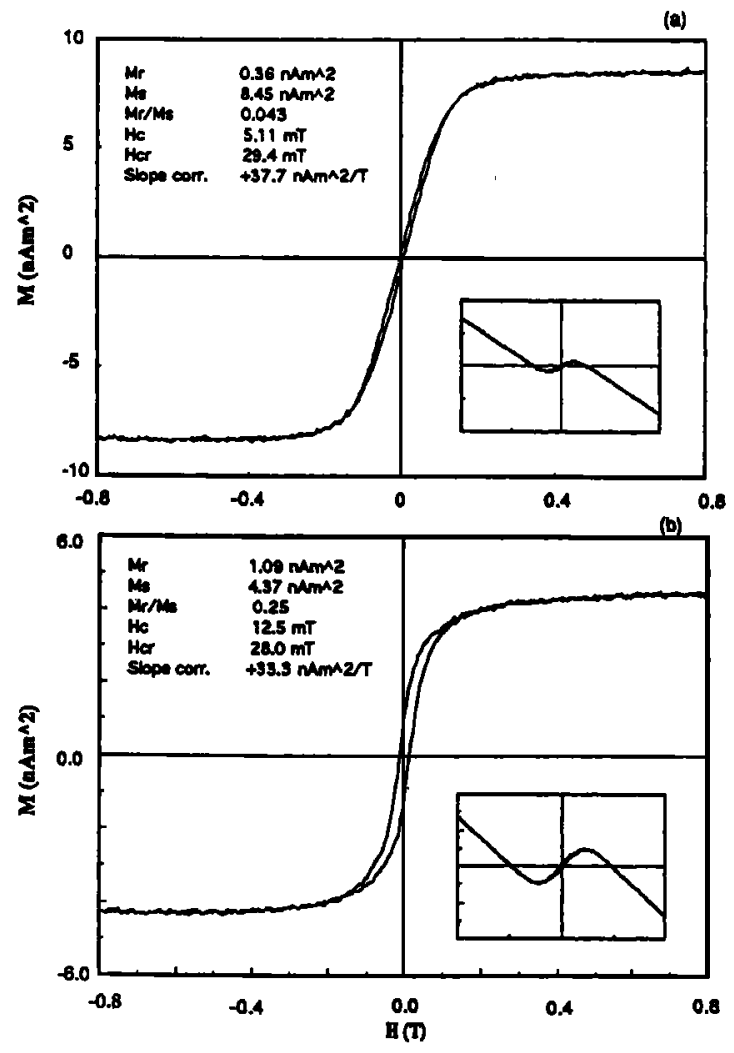

Figure 2. Hysteresis loops of individual magnetite spherules: (a) with dendritic surface texture, (b) with smooth surface texture. The insets show the loops as measured, before subtraction of the diamagnetic sample holder. 
(a)

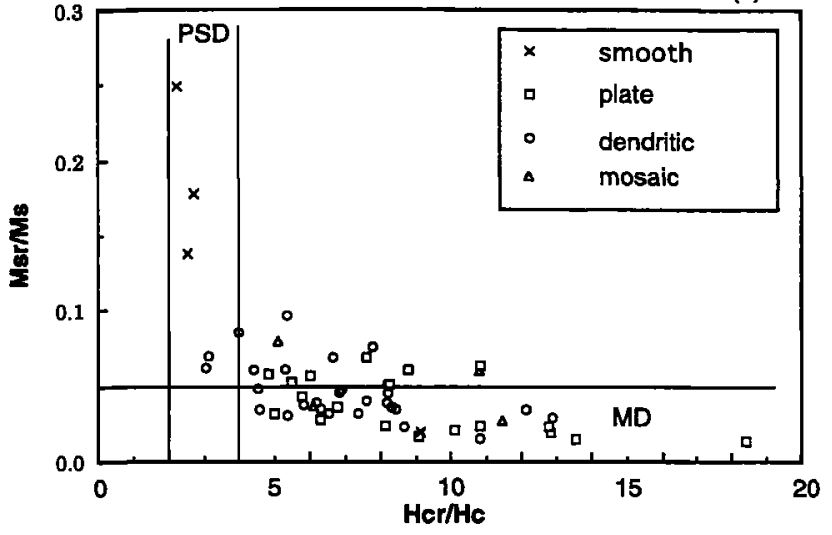

(b)

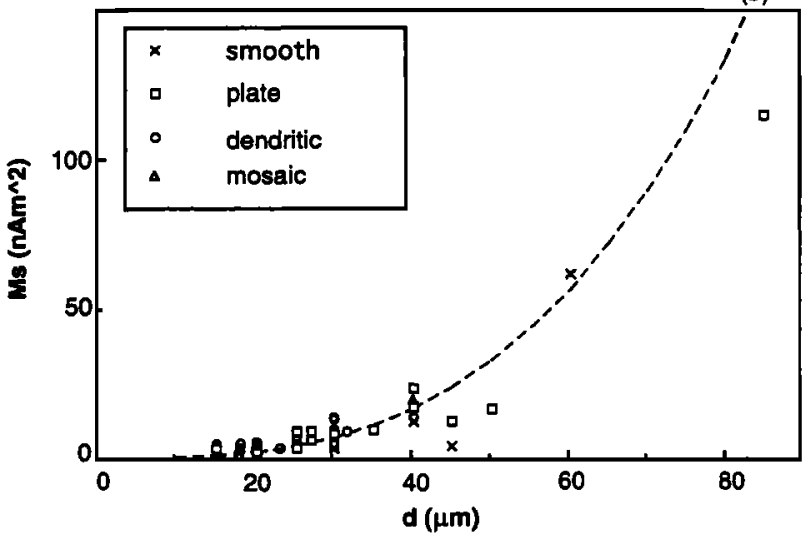

Figure 3. Hysteresis properties of magnetite spherules with different surface textures: (a) hysteresis ratios (after Day et al., 1977); (b) saturation magnetization vs. grain diameters; the dashed line is a theoretical function for solid magnetite spheres.

texture and a remanent coercivity to bulk coercivity ratio $\left(\mathrm{H}_{\mathrm{cr}} / \mathrm{H}_{\mathrm{c}}\right)$ of $<3$. All other grains have $\mathrm{M}_{\mathrm{sr}} / \mathrm{M}_{\mathrm{s}}$ ratios $<0.1$ and form a well-defined group in the plot of hysteresis ratios (Figure 3a) corresponding to multi-domain behavior, whereas data for the three smooth-surfaced grains plot in the PSD area [Day et al., 1977; Dunlop, 1986]. Based on the morphology and magnetic hysteresis properties, therefore, the spherules can be divided into two groups: Group A (mostly patterned and MD) and Group B (smooth and PSD). Of the 56 grains described in this study, only 4 grains have smooth surfaces and three of them belong to Group $B$.

The magnetization moment of the spherules is proportional to the cube of the grain diameter (Figure 3b). Using the density of magnetite $D=5300 \mathrm{~kg} / \mathrm{m}^{3}$ and the weight unit saturation magnetization $\mathrm{M}_{\mathrm{s}}=92 \mathrm{Am}^{2} / \mathrm{kg}$, the maximum moment of a pure, massive magnetite sphere is easily calculated. Values are plotted in Figure $3 \mathrm{~b}$. The measured data fit the theoretical curve reasonably well, indicating that most grains are not hollow as consistent with SEM observations that imply that only a few grains are hollow (e.g., Figure 1f). Data for the three smooth grains with $\mathrm{M}_{\mathrm{Sr}} / \mathrm{M}_{\mathrm{S}}$ value $>0.1$ plot below the theoretical values (Figure $3 \mathrm{~b}$ ) and are less than values for patterned grains with the same diameters, indicating that the smooth spherules may be hollow or composed of a combination of magnetite and non-magnetic minerals. Only one smooth grain (diameter of $60 \mu \mathrm{m}$ ) has an $\mathrm{M}_{\mathrm{S}}$ value slightly greater than the theoretical one. $\mathrm{M}_{\mathrm{Sr}} / \mathrm{M}_{\mathrm{S}}$ is $<0.03$ for this grain (Figure 3a). Because the grain with a diameter of $85 \mu \mathrm{m}$ was broken and therefore incomplete, its magnetic moment is less than the theoretical value.

Following measurements of magnetic data, selected grains were crushed between glass plates and fragments spread on holy-carbon coated copper grids for observation with the STEM. The size of the fragments obtained from patterned spheres ranges from 0.2 to $2 \mu \mathrm{m}$ (Figure $4 \mathrm{a}$ and $4 \mathrm{c}$ ). They give selected area electron diffraction (SAED) patterns with sharp diffraction spots (Figure 4b) that are characteristic of single crystals, in contrast to the ring-like SAED patterns of the polycrystalline magnetite that replaced pyrite [Suk et al., 1990; Xu et al., 1993]. The diffraction spots of other fragments are elongated as consistent with structural units of slightly different orientation, i.e. as consistent with a mosaic structure. For example, the spots in Figure $4 \mathrm{~d}$ are elongated as if rotated around the central beam, implying that the fragment that produced the pattern consists of subunits with slightly different orientations, as would be expected on the basis of the grain surface textures (e.g., Figure 1d). Fragments obtained from smooth-surfaced spheres also give SAED patterns with sharp diffraction spots. The size of these fragments was similar to that of fragments from patterned spheres.

To verify the overall crystalline status of the spherules, two spheres with diameters of 45 and $50 \mu \mathrm{m}$ from Group A were selected and mounted on a single crystal $X$-ray diffraction precession machine. The resulting diffraction pattern obtained from a grain with a platy surface has individual reflections arranged in circles, whereas a pattern obtained from a grain with a dendritic surface has individual reflections representing superimposed reciprocal lattices of magnetite. These diffraction patterns show that the spherules are polycrystalline, but consist of a finite number of individual crystals with different crystallographic orientations, as consistent with the SEM and STEM observations.

\section{Discussion and Conclusions}

Magnetite spherules in remagnetized Paleozoic carbonates from the Appalachian Basin have been considered to be

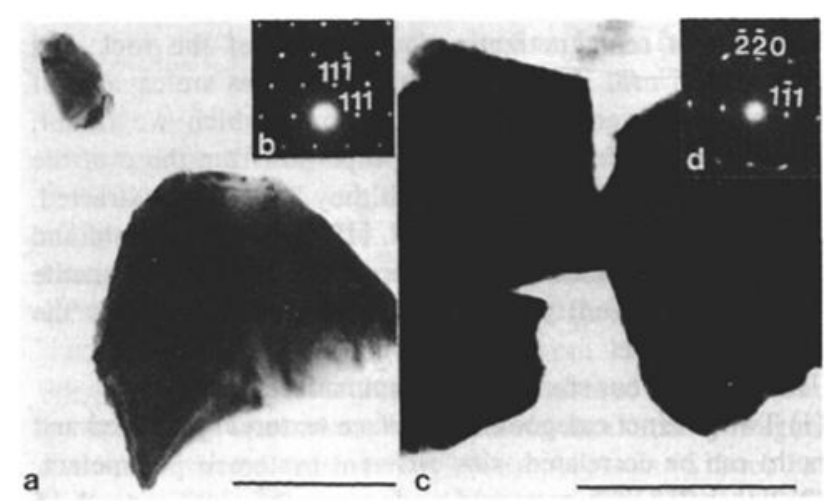

Figure 4. STEM images of crushed spherule particles: (a) bright field image of crushed fragment from a sphere with dendritic surface texture, (b) SAED pattern obtained from the upper left grain in (a), (c) bright field image of crushed fragments from a sphere with platy surface texture, (d) SAED pattern of the left grain in (c). Scale bar $=0.5 \mu \mathrm{m}$. 
diagenetic minerals carrying an ancient, yet secondary remanence [McCabe et al., 1983]. Subsequently, magnetite spherules were found in many other carbonate formations that were also observed to have formed after pyrite [Suk et al., 1990].

SEM observations show that most magnetite spherules extracted from carbonates have patterned surface textures (Group A). They show textures that we infer to have formed during crystallization, such textures sometimes extending to the interior of grains (Figure 1e). Many of the magnetite spherules are different from those produced by replacement of pyrite framboids and described by Suk et al. [1990]. The latter consist of authigenic octahedral crystals of pyrite which have been replaced entirely or in part by magnetite. Because magnetite and pyrite have different crystal structures, the replacing magnetite consists of an array of randomly-oriented crystallites with orientation unrelated to that of the original pyrite octahedra. In the case of the spherules studied here, the external crystal faces reflect locally well-crystallized singlecrystal domains of magnetite. We tentatively postulate that, if the two kinds of spheres are related, those described in this study must be derived from the pseudoframboids by dissolution and recrystallization, as only such a process can give rise to the very different textures. It is clear, however, that the magnetic properties of the pseudoframboids are those of magnetite consisting of multiple domains.

Day et al. [1977] concluded that MD magnetite grains have typical hysteresis parameters: $\mathrm{H}_{\mathrm{C}} \approx 3 \mathrm{mT}, \mathrm{M}_{\mathrm{Sr}} / \mathrm{M}_{\mathrm{S}} \leq 0.05$, and $\mathrm{H}_{\mathrm{cr}}>4 \mathrm{H}_{\mathrm{c}}$. The magnetite spherules extracted from the Twin Creek Limestone and the Leadville Limestone can be grouped into two types according to their hysteresis properties (Figure 3a). One type (the 3 Group B, smooth-surfaced spherules) have $\mathrm{M}_{\mathrm{Sr}} / \mathrm{M}_{\mathrm{S}}>0.1, \mathrm{H}_{\mathrm{c}}>12 \mathrm{mT}$, and $\mathrm{H}_{\mathrm{cr}} / \mathrm{H}_{\mathrm{c}}<3$. The other type (all Group A spherules and one Group B spherule) have $\mathbf{M}_{\mathbf{S r}} / \mathbf{M}_{\mathbf{S}}$ $<0.1, \mathrm{H}_{\mathrm{c}}<10 \mathrm{mT}$, and $\mathrm{H}_{\mathrm{cr}} / \mathrm{H}_{\mathrm{c}}>3$, although they have $\mathrm{H}_{\mathrm{cr}}$ values similar to those of Group $B$. In addition, the $H_{C}$ values of Group A grains reveal a power law dependence on particle size, with $H_{c}$ proportional to $d^{-0.63}$. This value is similar to the value $\mathrm{d}^{-2 / 3}$ predicted by Neel's simple theory for the nucleation of large MD structures [Dunlop, 1986]. Therefore, we conclude that Group A magnetite spherules are undoubtedly MD in character, although some of them have $\mathrm{M}_{\mathrm{Sr}} / \mathrm{M}_{\mathbf{S}}>0.05$.

The alternating field demagnetization data [McWhinnie et al., 1990] of the Twin Creek Limestone indicated that the stable ancient remagnetization component of the rock had coercivity $>45 \mathrm{mT}$. Even if Group A spherules are capable of carrying stable ancient remagnetizations, which we doubt, they have very different magnetic properties from those of the bulk carbonate samples from which they have been extracted. Thus, as also surmised by Suk et al. [1992] and Halgedahl and Suk [1992], we conclude that it is a different type of magnetite (submicrometer sized) and not the spherules, which carry the ancient remanence.

The results of our study can be summarized as follows:

(1) Two distinct categories of surface textures (patterned and smooth) can be correlated with different hysteresis parameters.

(2) Spherules with patterned surfaces in the size range of 15 to $85 \mu \mathrm{m}$ show MD magnetic characteristics.
(3) Spherules with patterned surfaces (dominant in the rocks of this study) are unlikely to carry stable ancient remanences.

Acknowledgments. We thank B. van der Pluijm for providing samples from the Twin Creek limestone, B. Housen and C. Richter for their help with trial hysteresis measurements, D. Suk for help with sample preparation, $C$. Hunt for helping with the measurements at the IRM, and R. Reynolds and an anonymous reviewer for helpful comments. This study was supported by a $S$. Tumer grant from the Department of Geological Sciences at the University of Michigan and an IRM visiting scholarship at the University of Minnesota.

\section{References}

Buerger, M. J., Crystal-structure analysis, 668 pp., John Wiley \& Sons Inc., New York, 1960.

Day, R., M. Muller, and V. A. Schmidt, Hysteresis properties of titanomagnetites: Grain-size and compositional dependence, Phys. Earth Planet. Int., 13, 260-267, 1977.

Dunlop, D. J., Hysteresis properties of magnetite and their dependence on particle size: a test of pseudo-single-domain remanence models, Jour. Geophys. Res., 91, 9569-9584, 1986.

Halgedahl, S., and D. Suk, 1992, On the carriers of remanence in Paleozoic platform carbonates of North America, 11.: Demagnetization characteristics of magnetite spherules vs. wholerock specimens from the Onondaga Formation, Eos Trans. AGU 73, $154,1992$.

Horton, R. A., J. W. Geissman, and R. J. Tschauder, Paleomagnetism and rock magnetism of the Mississippian Leadville (Carbonate) Formation and implications for the age of sub-regional dolomitization, Geophys. Res. Letters, 11, 649-652, 1984.

Jackson, M., Diagenetic sources of stable remanence in remagnetized Paleozoic cratonic carbonates: a rock magnetic study, Jour. Geophys. Res., 95, 2753-2761, 1990.

McCabe, C., R. Van der Voo, D. R. Peacor, C. R. Scotese, and R. Freeman, Diagenetic magnetite carries ancient yet secondary remanence in some Paleozoic sedimentary carbonates, Geology, 11, 221-223, 1983.

McWhinnie, B. A. Van der Pluijm, and R. Van der Voo, Remagnetizations and thrusting in the Idaho-Wyoming Overthrust Belt, Jour. Geophys. Res., 95, 4551-4559, 1990.

Suk, D., and S. Halgedahl, On the carriers of remanence in Paleozoic platform carbonates from North America, I: hysteresis properties of individual magnetite spherules vs. whole specimens (abstract), Eos, Trans. AGU 73, 153,1992.

Suk, D., D. R. Peacor, and R. Van der Voo, Replacement of pyrite framboids by magnetite in limestone and implications for paleomagnetism, Nature, 354, 611-613, 1990.

Suk, D., R. Van der Voo, and D. R. Peacor, SEM/STEM observation of magnetic minerals in presumably unremagnetized Paleozoic carbonates from Indiana and Alabama, Tectonophysics, 215, 255275, 1992.

$\mathrm{Xu}$, W., Rob Van der Voo, and Donald R. Peacor, SEM/STEM observation of magnetic minerals in the Twin Creek limestone, Wyoming (abstract), Eos, Trans. AGU 74, 114, 1993.

Donald R. Peacor, Rob Van der Voo, and Weixin Xu, Department of Geological Sciences, University of Michigan, Ann Arbor, MI 48109. 1063

(Received: November 29,1993; accepted: January 10, 1994) 